
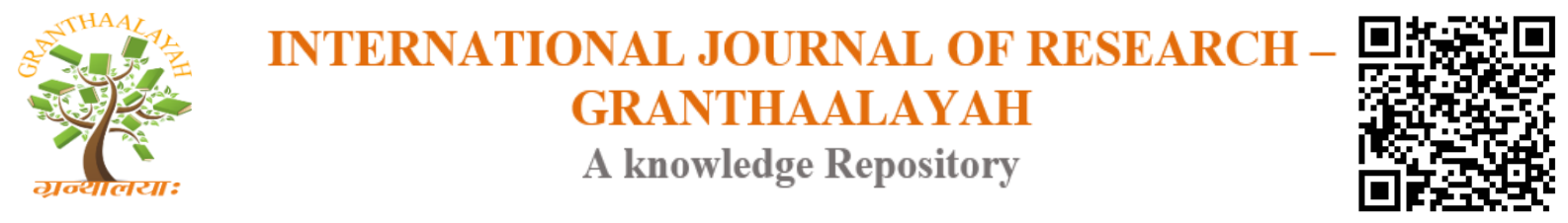

Science

\title{
AWARENESS ROLE AMONG MALARIA CONTROL WORKERS IN REDUCING INSECTICIDES RISKS, BAHRI LOCALITY, KHARTOUM CITY, SUDAN
}

\author{
Ibrahim Emaeldin ${ }^{1}$, Fatima Fadul Ali ${ }^{2}$, Mohamed Osman Elamin ${ }^{3}$, Elfatih Aburass ${ }^{4}$ \\ ${ }^{1}$ Ministry of Health, Sudan \\ ${ }^{2}$ Alzaiem Alazhri University, Sudan \\ ${ }^{3}$ Umm AlQura University, Faculty of Public Health \& Informatics \\ ${ }^{4}$ Ministry of Health, Saudi Arabia
}

\begin{abstract}
The use of insecticide leads to considerable health hazards for people, due to direct contact during application, contamination of food or drinking water. The effects of the dispersal and negligent handling of insecticide are a significant global health problem. WHO, estimated that one million unintentional acute insecticide poisonings occurred worldwide annually. It was expected that 735,000 cases of specific chronic effects and 37,000 unspecific health effects such as forms of cancer would occur annually. This emphasizes the role of awareness as a core element in protection of handlers.

The study was conducted as a quasi-experimental design in BahrI locality among Malaria Control workers to assess the effect of health education on knowledge attitude and practice among Malaria Control Workers towards Chemical Insecticide Handling during the period of 2014- 2016 .

A sample size of 80-targeted workers was taken by total Coverage due to the limited number of workers. Data was collected by questionnaire, observation, interviews and Reports and records.

The methods used in intervention includes; training of trainers, lectures on insecticides hazard for human being and environment safe insecticides handling, posters to explain the lectures , pamphlets about safe handling of insecticides and about insecticides poisoning and first aid of insecticides Poisoning and videos to reinforce the lectures. In addition use a comprehensive questionnaire pre and post to evaluate the effect of health education. Data collected was analyzed manually and by computer using SPSS program.

The results revealed that knowledge of workers about the hazards of insecticides to human health increased from $80 \%$ in pre-test to $100 \%$ after the intervention. The results also showed there is an improvement of the positive attitude towards the prevention of insecticides hazards from $92 \%$ to $100 \%$ after intervention due to health education intervention. Health education intervention increases the positive behavior of workers regards eat, drinking and smoking while handling insecticides to $100 \%$ of Malaria Control Workers in post- test believe that insecticides enter to body through inhalation while in the pre- test percentage was $85 \%, 90 \%$ of Workers in post- test believes that insecticides enter to body through eating and drinking during work, while in the pre- test percentage was $70 \%$ and $100 \%$ of Workers in post-test believe that the insecticides
\end{abstract}


enter to body through Skin while in the pre- test the percentage was $65 \%$.that was due to health education intervention

The study concluded that health education had a remarkable improvement in knowledge attitude and practice among Malaria Control Workers and all those who were handling insecticides.

The study recommended that extensive health education programs, training, required to improve the knowledge, attitudes and practices of all workers about Chemical Insecticide Handling in Bahri Locality.

Further studies are needed to determine protective measures.

Keywords: Malaria Control; Workers; Reducing Insecticides.

Cite This Article: Ibrahim Emaeldin, Fatima Fadul Ali, Mohamed Osman Elamin, and Elfatih Aburass. (2017). "AWARENESS ROLE AMONG MALARIA CONTROL WORKERS IN REDUCING INSECTICIDES RISKS, BAHRI LOCALITY, KHARTOUM CITY, SUDAN." International Journal of Research - Granthaalayah, 5(9), 132-144. https://doi.org/10.29121/granthaalayah.v5.i9.2017.2223.

\section{Introduction}

An estimated three billion people, almost half of the world's population, live in areas where malaria transmission occurs. Malaria is endemic in one hundred and seven countries and territories in tropical and subtropical regions, but there are substantial geographic disparities in the disease burden. (1)

World Health Organization estimates that in 2015, two hundred and fourteen million clinical cases of malaria occurred, and 438,000 people died of malaria, most of them children in Africa. Because malaria causes so much illness and death, the disease is a great drain on many national economies. Since many countries with malaria are already among the poorer nations, the disease maintains a vicious cycle of disease and poverty. (2)

Malaria in Sudan is a major public health problem the size of the malaria problem annually is estimated about 3.9 million cases and 3 thousand deaths, and these figures equal to $32.8 \%$ of the cases and $19.2 \%$ of deaths in the Middle East region.(1)

Economic impact of malaria in Sudan has not been studied extensively, but the known of them is great. Malaria leads to the loss of $22 \%$ of the working days as they lead to the loss of $40 \%$ of the harvest. Reduce cases and deaths needs large continuous work of cost 7-10 million dollars annually for a period not less than 4 years. (3)

There is a high burden of malaria-related morbidity and mortality in Sudan. However, the national malaria control program, with WHO's support, has reduced the number of malaria cases from more than four million in 2000 to less than one million in 2010. Between 2001 and 2010, the number of deaths due to malaria was reduced by $75 \%$. (1) 
Vector control is a cornerstone of malaria control and it remains the most generally effective measure to prevent malaria transmission and therefore is one of the strategic approaches to malaria control.(1)

Around the globe, chemical-synthetic pesticides have been used increasingly since the 1940s. Their use lead to considerable health hazards for people, due for example to direct contact during application, pesticide drift from fields, or contamination of food or drinking water. The effects of the dispersal and negligent handling of pesticides are a significant global health problem (4) Between 2005 and2010, the total volume of global sales rose from US\$ 31 billion to US\$ 38 billion. The amount of pesticides used internationally has risen fifty-fold since 1950.(4)

A person can use daily an insecticide for the control of the insects, exposing itself every day in small quantity, but the amount of pesticide that is concentrated in the body, increase progressively, until after a time it becomes a toxic dose. Then it will be toxic when the poisoning to these insecticides has taken place.(5)

In 1990 the WHO estimated that one million unintentional acute pesticide poisonings occurred worldwide annually. However, only the most severe cases registered was in hospitals. WHO later reported that the extent of poisonings was significantly underestimated at the time. Despite this admission and the fact that, after more than twenty years,. What is more, funding for a WHO project on the epidemiology of pesticide poisoning was discontinued several years ago. The number of people who died worldwide as a result of unintentional poisonings was estimated as 20,000 in 1990 more current statistics have become available since 2008. According to this WHO data, 346,000 people die annually worldwide as a result of unintentional poisonings, twothirds of them in developing countries. Here, too, the WHO admits that this figure may be too low The substances involved are not specified, but presumably most of these poisonings are caused by toxic chemicals such as pesticides researchers have noted that probably $71 \%$ of these fatalities might have been prevented by improving chemical safety measures(4)

Statistics on chronic poisonings are very limited, since registration systems and regional studies only include poisoning cases that can be proven without any doubt to have been caused by pesticide exposure. According to a 1990 WHO estimate, it was expected that 735,000 cases of specific chronic effects and 37,000 unspecific health effects such as forms of cancer would occur annually.(4)

Moreover, especially in developing countries, a large number of highly hazardous pesticides are easily available, many of which are used, often even without appropriate protective clothing. Because of their availability (4)

Statistics on illnesses due to chronic poisoning as a result of pesticide use or pesticide contamination of food are very limited. But there is reliable evidence that the increasing incidence of cancer, hormonal effects, and neurological disorders (4) 


\section{Objectives of the Study}

\subsection{General Objective}

The Effect of Health Education on Knowledge, Attitude and Practices among Malaria Control Workers towards Chemical Insecticide Handling 2014-2016.

\subsection{Specific Objectives}

- To assess the present situation of knowledge, attitude and practices of Malaria Control workers.

- To increase awareness of workers regarding insecticides and hazards

- To improve the attitudes of workers regarding insecticide handling and hazards

\section{Materials and method}

\subsection{Study Design}

A quasi-experimental Study was conducted in Bahri Locality among malaria control workers

\subsection{Study Area}

\subsubsection{Geographical Description}

Locality of Khartoum Bahri is located between the Blue Nile from theSouth and boundaries of the River Nile state (at Garri village) from North. It is adjacent to locality of East Nile on the East and is bordered by the River Nile on the West.

\subsubsection{Area}

The locality covers an area of about $455 \mathrm{~km} 2$.

\subsubsection{Administrative Units}

The three administrative units are named as follows:

- Bahri administrative unit.

- BahriNorth unit.

- The unit of northern countryside.

\subsection{Study Population}

According to 2003- 2008 Census, the population of the locality is about 533,700 inhabitants. However, the massive migration has increased the number of the inhabitants close to 800,000 citizens out of the various tribes of the Sudan. 
The target population ismalaria control workers whom were handling the chemical insecticides in Bahrilocality were about 80 workers. (38Larval control Workers, 9 Fog workers, 4 Storage workers, 29 Supervisors).

\subsection{Sample Size}

Due to the limited number of workers, total coverage of 80 workers was undergone.

\subsection{Data Collection}

Preliminary survey was conducted in order to assess Knowledge, attitudes and practices of malaria control workers towards chemical insecticide handling using the following methods:

\section{A. Questionnaire}

Appropriate questionnaire was used to assess Knowledge, attitudes and practices of malaria control worker related to chemical insecticide handling. The questionnaire contains the following variables insecticides hazards, Usage of self-protection measures, Safe disposal of insecticides waste. (Annex NO $\underline{9}$ )

\section{B. Observation}

Observation focused on workers behavior towards the right handling of insecticides and the usage of personal protection measures.

\section{Interviews}

Supervisors were interviewed for their responsibilities towards the workers safety and provision of protective measures. (Annex NO $\underline{8}$ )

\section{Reports and records}

To gain information about the workers task and reported case of poisoning and medical examination among the workers.

\subsection{Intervention}

Intervention for six months from September 2015 to March 2016 for three groups through:

\section{Training of Trainers:}

Trained three groups of trainers on insecticides hazards toward human being and environment, safe Insecticides handling, Prevention method from the insecticides hazards, use of selfprotection measures, Safe disposal of insecticides waste, first aid of insecticides poisoning and how to explain it to workers

\section{Lectures:}

Three lectures per month for each group of workers on the topics of Training lecture: Insecticide hazard for human being and environment safe Insecticide handling, prevention method from the insecticide hazards, Use of self-protection measures, Safe disposal of insecticide waste, insecticides Poisoning and First aid of insecticide Poisoning(Annex NO 4-5). 


\section{Posters:}

Posters ware used for each group,to explain (with the lectures), Poster contain 9 massages about (how to protect yourself from insecticides hazards), posterpasted in pleases of worker meeting every day (Annex NO 1-2-3)

\section{Pamphlets:}

Explained and distributed 60 folded about safe handling of insecticides and 60 folded about insecticides poisoning and first aid of insecticides poisoning.

\section{Video:}

Used in training of trainers to explain the personal protective equipment and how wear it

\subsection{Monitoring and Evaluation}

There was follow up of intervention and monitoring for six months concerning knowledge, attitude and practice of the participants through checklist, observation of practices.

There was an implementation of the same questionnaire, observation and interviews after the intervention to make comparison between pre and post questionnaire to assess the effect of health education.

\subsection{Data analysis}

The data was statistically analyzed manually and using computer software, using Statistical Package for Social Sciences (SPSS) program, and t-test has been used to examine the comparison had been done before and after intervention in term of level of knowledge, attitudes and practice to determine the intervention effectiveness and a full set of tables and graphs was prepared.

\section{Results}

Knowledge about types of insecticides among Malaria Control Workers Bahri Locality 20152016

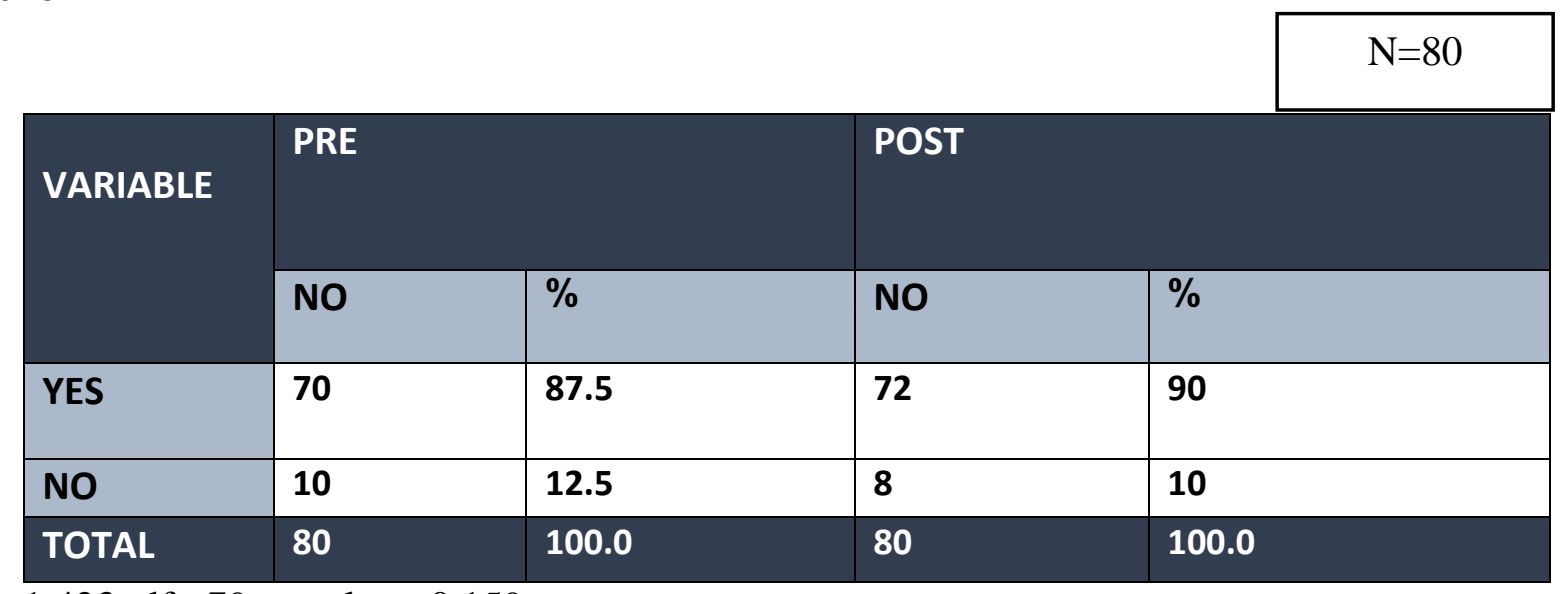

$\mathrm{T}=1.423 ; \mathrm{df}=79 ; \mathrm{p}$-value $=0.159$

There is insignificant increase in knowledge of the malaria control workers regarding type of insecticides from $87.5 \%$ to $90 \%$ after the interventiont-test $=1.423$ p-value $=0.159$ showing no significant change. 


\section{Table No (2)}

Knowledge about type of insecticides among Malaria Control Workers, Bahri Locality 2015-2016

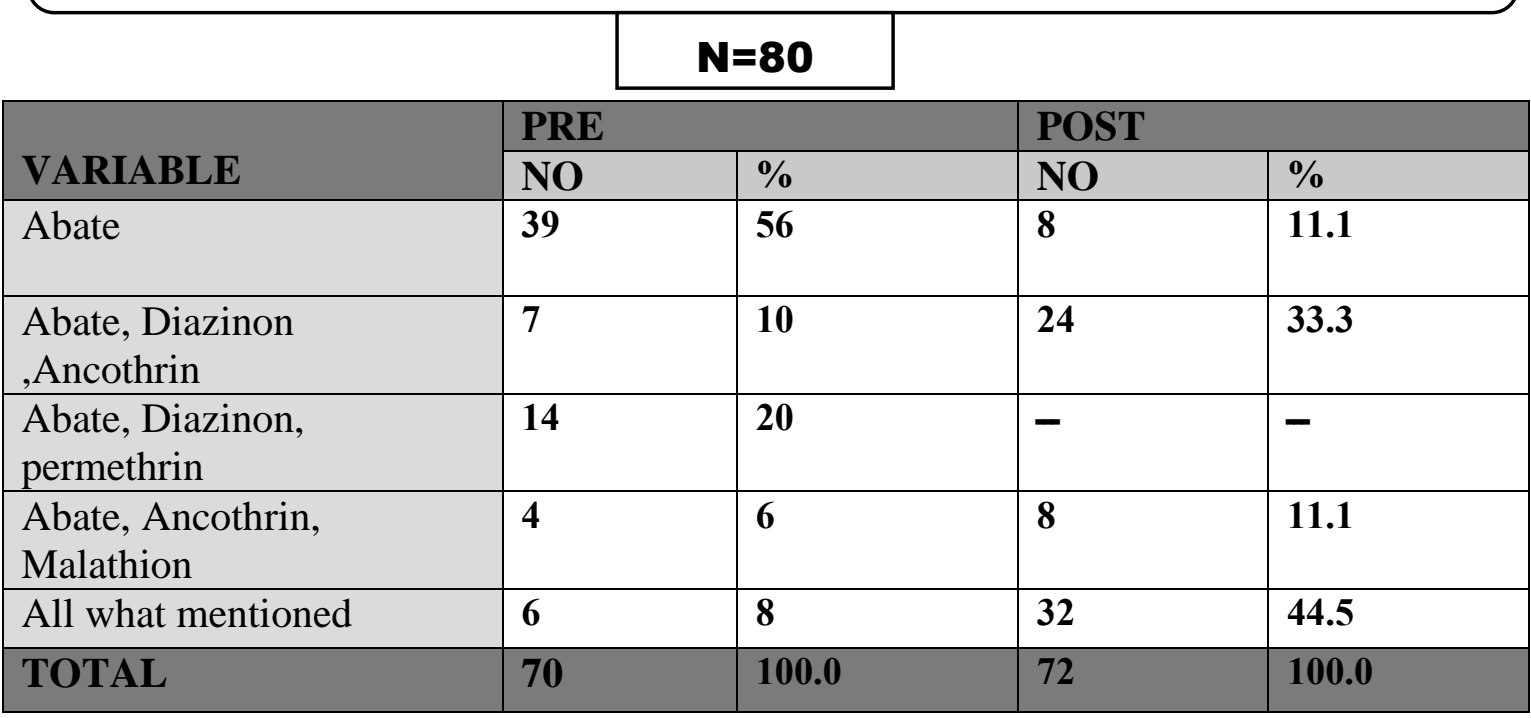

$\mathrm{T}=5.396 ; \mathrm{df}=69 ; \mathrm{p}$-value $($ significant $)=0.000$

Most of workers $56 \%$ mentioned only abate as knowledge of insecticides, while, most of workers $44.5 \%$ in post -test mentioned all of insecticides $(t$ test $=5.396 p$-value $=0.000)$ showing high significant change.

\section{Table No (3)}

Knowledge about if there were insecticide hazards to human health among Malaria Control Workers, Bahri Locality 2015-2016

\begin{tabular}{|c|c|c|c|c|}
\hline \multirow{2}{*}{ VARIABLE } & \multicolumn{2}{|l|}{ PRE } & \multicolumn{2}{|c|}{ POST } \\
\hline & NO & $\%$ & NO & $\%$ \\
\hline YES & 68 & 85 & 80 & 100 \\
\hline NO & 12 & 15 & 0 & 0 \\
\hline TOTAL & 80 & 100.0 & 80 & 100.0 \\
\hline
\end{tabular}

$\mathrm{T}=3.734 ; \mathrm{df}=79 ; \mathrm{p}$-value (significant) $=.000$ 
There is a high significant increase in knowledge among the malaria control workers concerning the hazard of insecticides to human being from $80 \%$ to $100 \% \quad(\mathrm{t}$ test $=3.734 \mathrm{p}$-value $=0.000$ ) showing highly significant change

\section{Table No. (4)}

Knowledge about the types of insecticides hazards to human among Malaria Control Workers, Bahri Locality 2015-2016

\begin{tabular}{|l|l|l|l|l|}
\hline \multirow{2}{*}{ VARIABLE } & PRE & \multicolumn{3}{l|}{ N=80 } \\
\cline { 2 - 5 } & NO & $\%$ & POST \\
\hline Allergy & 37 & 55 & 12 & 15 \\
\hline Poisoning & & & & \\
\hline Allergyand Poisoning & 13 & 19 & 16 & 20 \\
\hline All what mentioned & 13 & 19 & 16 & 20 \\
\hline TOTAL & 5 & 7 & 36 & 45 \\
\hline
\end{tabular}

$\mathrm{T}=11.592 ; \mathrm{df}=67 ; \mathrm{p}$-value $($ significant $)=.000$

Table illustrated most of workers 55\% mentioned only allergy as knowledge of insecticides hazards in pre- test, while, most of workers $45 \%$ in post- test mentioned all type of insecticides hazardst test $=11.592 \mathrm{p}$-value $=0.000)$ showing high significant change. (

\section{Table No (5)}

Distribution of illnesses due to insecticides handling among Malaria Control Workers, Bahri Locality 2015-2016

\begin{tabular}{|c|c|c|c|c|}
\hline & & & & \\
\hline \multirow{2}{*}{ VARIABLE } & \multicolumn{2}{|l|}{ PRE } & \multicolumn{2}{|c|}{ POST } \\
\hline & NO & $\%$ & NO & $\%$ \\
\hline YES & 16 & 20 & 18 & 22.5 \\
\hline NO & 64 & 80 & 62 & 77.5 \\
\hline TOTAL & 80 & 100.0 & 80 & 100.0 \\
\hline
\end{tabular}

$\mathrm{T}=1.423 ; \mathrm{df}=79 ; \mathrm{p}$-value $($ significant $)=0.159$ 
Table showed that $20 \%$ of Malaria Control Workers in pre- test have illness due to insecticides while in the post test percentage was $22.5 \%$ ( $t$ test $=1.423$ ) $\quad$-value $=0.159$ showing insignificant change.

\section{Table No (6)}

Distribution of the type of illness due to insecticides handling among Malaria Control Workers Bahri Locality 2015-2016

\begin{tabular}{|c|c|c|c|c|}
\hline & & $=80$ & & \\
\hline \multirow{2}{*}{ VARIABLE } & \multicolumn{2}{|l|}{ PRE } & \multicolumn{2}{|c|}{ POST } \\
\hline & NO & $\%$ & NO & $\%$ \\
\hline Respiratory problems & 3 & 18.75 & 3 & 17 \\
\hline skin allergy & 6 & 37.5 & 5 & 28 \\
\hline Eye allergy & 4 & 25 & 8 & 44 \\
\hline $\begin{array}{l}\text { Respiratory problems and } \\
\text { Eye allergy }\end{array}$ & 3 & 18.75 & 2 & 11 \\
\hline TOTAL & 16 & 100.0 & 18 & 100.0 \\
\hline
\end{tabular}

Most of workers $37.5 \%$ in pre-test have skin allergy, while, most of workers $44 \%$ in post-test mentioned Eye allergy

\section{Table No (7)}

Knowledge of Malaria Control Workers about insecticides entry to human body, Bahri Locality 2015-2016

\begin{tabular}{|c|c|c|c|c|c|}
\hline & & & & & \\
\hline & & PRE & & PO: & \\
\hline VARIABLE & & NO & $\%$ & NO & $\%$ \\
\hline inhalation & YES & 68 & 85 & 80 & 100 \\
\hline & NO & 12 & 15 & 0 & 0 \\
\hline TOTAL & & 80 & 100.0 & 80 & 100.0 \\
\hline Eating and drinking & YES & 56 & 70 & 72 & 90 \\
\hline during work & NO & 24 & 30 & 8 & 10 \\
\hline
\end{tabular}


DOI: 10.5281/zenodo.999445

\begin{tabular}{|l|l|l|l|l|l|}
\hline TOTAL & 80 & 100.0 & 80 & 100.0 \\
\hline \multirow{3}{*}{ Skin } & YES & 52 & 65 & 80 & 100 \\
\cline { 2 - 7 } & NO & 28 & 35 & 0 & 0 \\
\hline \multirow{2}{*}{ TOTAL } & & 80 & 100.0 & 80 & 100.0 \\
\hline
\end{tabular}

Table showed that $100 \%$ of Malaria Control Workers in post- test believe that insecticides enter to body through inhalation while in the pre- test percentage was $85 \%, 90 \%$ of Workers in posttest is believe that insecticides enter to body through Eating and drinking during work, while in the pre- test percentage was $70 \%$ and $100 \%$ of Workers in post-test believe that the insecticides enter to body through Skin while in the pre- test the percentage was $65 \%$.

\section{Table No (B)}

Knowledge of Malaria Control Workers about insecticide hazards to environment, Bahri Locality 2015-2016

\begin{tabular}{|l|l|l|l|l|l|}
\hline \multicolumn{2}{|c|}{} & N=80 & \multicolumn{2}{l|}{} \\
\hline \multirow{3}{*}{ VARIABLE } & PRE & NO & $\%$ & POST & NO \\
\hline YES & 50 & 62.5 & 72 & 90 \\
\hline NO & 30 & 37.5 & 8 & 10 \\
\hline TOTAL & 80 & 100.0 & 80 & 100.0 \\
\hline
\end{tabular}

$\mathrm{T}=5.474 ; \mathrm{df}=79 ; \mathrm{p}$-value $($ significant $)=0.000$

There is a high significant increase in knowledge among the malaria control workers concerning the hazard of insecticides to environment from $62.5 \%$ to $90 \%$ after intervention. $(\mathrm{t}$ test $=5.474 \mathrm{p}$ value $=0.000$ ) showing high significant change.

\section{Table No (\$)}

Knowledge of Malaria Control Workers about type of insecticide hazard to environment, Bahri Locality 2015-2016

\section{$\mathbf{N}=\mathbf{8 0}$}

\begin{tabular}{|l|l|l|l|l|}
\hline \multirow{2}{*}{ VARIABLE } & PRE & POST & \multicolumn{2}{l|}{} \\
\cline { 2 - 5 } Water pollution & NO & $\%$ & NO & $\%$ \\
\hline
\end{tabular}




\begin{tabular}{|l|l|l|l|l|}
\hline air pollution & 11 & 22 & 12 & 17 \\
\hline Soil contamination & 1 & 2 & - & - \\
\hline $\begin{array}{l}\text { Soil contamination and } \\
\text { Water pollution }\end{array}$ & 3 & 6 & 8 & 11 \\
\hline All what mentioned & 8 & 16 & 44 & 61 \\
\hline TOTAL & 50 & 100.0 & 72 & 100.0 \\
\hline
\end{tabular}

$\mathrm{T}=7.846 ; \mathrm{df}=49 ; \mathrm{p}$-value $($ significant $)=0.000$

Table illustrated most of workers $54 \%$ mentioned only Water pollution as a hazard of insecticides to environment, while most of workers $61 \%$ in post- test mentioned all mentioned insecticides hazards to environment. $\mathrm{T}$ test $=7.846 \mathrm{p}$-value $=0.000$ showing high significant change.

\section{Table No (10)}

Knowledge of Malaria Control Workers about preventable insecticide hazards, Bahri Locality 2015-2016

\begin{tabular}{|c|c|c|c|c|}
\hline & & & & \\
\hline \multirow[b]{2}{*}{ VARIABLE } & \multicolumn{2}{|l|}{ PRE } & \multicolumn{2}{|c|}{ POST } \\
\hline & NO & $\%$ & NO & $\%$ \\
\hline YES & 74 & 92.5 & 80 & 100 \\
\hline NO & 6 & 7.5 & 0 & 0 \\
\hline TOTAL & 80 & 100.0 & 80 & 100.0 \\
\hline
\end{tabular}

$\mathrm{T}=2.531 ; \mathrm{df}=79 ; \mathrm{p}$-value $($ significant $)=0.013$

There is a significant increase in knowledge among the malaria control workers concerning preventING insecticide hazards from $92.5 \%$ to $100 \%$ after intervention ( $\mathrm{t}$ test $=2.531 \mathrm{p}$-value $=$ 0.013 ) showing a significant change.

\section{Discussion}

Knowledge about type of insecticides in the pre - test most of workers (56\%) mentioned only abate and in the post- test most of them (44.5\%) mentioned all mentioned insecticides (Abate, Diazinon, permethrin, Ancothrin, Malathion) this, showed a significant increase $(\mathrm{P}<0.05)$ .This was due to the health education intervention. Npic and PARK (2011) illustrated that Insecticides are classified into three groups; contact poisons, stomach poisons and fumigants. 
The study indicated that most of the respondents $(85 \%)$ believed that insecticides are hazardous to human health in pre- test and in post- test $\mathrm{s}$ all of them (100\%)believed that insecticides are hazardous to human health showing significant increase $(\mathrm{P}<0.05)$ this agrees with PAN Germany (2012), which stated that" The many chemical substances that are collectively referred to as pesticides intervene in different vital metabolic processes in various organisms. The effects of insecticides range from damage to the transmission of nerve impulses and inhibition of blood clotting to paralysis of the respiratory and circulatory centers".(5)

The study indicated that Knowledge of workers about the route of entry of insecticides to the body was increased due to intervention. The Knowledge about inhalation increased from( $85 \%)$ to $(100 \%)$. The knowledge about insecticide entry to the body during eating and drinking increased from $(70 \%)$ to $(90 \%)$ and the Knowledge about insecticide entry to the body through skin increased from(65\%) to (100\%). This agreed with Canadian center for occupational health and safety Pesticides which mentioned that insecticides can enter body during mixing, applying, or clean-up operations. There are generally three ways a chemical can enter the body: through the skin (dermal) through the lungs (inhalation), or by mouth (ingestion).(6)

The result showed that the knowledge of workers about the hazard of insecticides to environment increased from(62.5\%)to (90\%) after the intervention, showing high significant change $(\mathrm{P}<0.05)$.This agrees with National Pesticide Information Center (NPIC) ( 2016) which illustrated that Diazinon applied to soil can last for weeks or even months depending on the soil environment. Diazinon has the potential to dissolve in water, move through soils and contaminate groundwater.

\section{Conclusion}

This Study concluded that health education had a remarkable improvement in knowledge, attitude and practice of Malaria Control Workers about Chemical Insecticide Handling in Bahri Locality.

This study concluded that the hazard of insecticides to the malaria control workers can be tackled by appropriate health education intervention .The health education interventions caused a remarkable increase in the knowledge, attitudes of the malaria control workers.

\section{Recommendations}

\section{Based on the objectives and the results obtained, the study recommended the followings: Actions should be taken by responsible authority:}

1) Extensive health education programs and courses periodically to all workers and all those who are handling insecticides.

2) To ensure proper storage and disposal of insecticides waste and container

3) To designate training program for the workers.

4) To provide the first aid boxes in each administrative unit.

\section{References}

[1] Malaria epidemic 2013. Accessed November 15, 2013, www.who.int/malaria/en 
[2] World Malaria Report 2016. Accessed January 19, 2017, http://www.who.int/malaria/publications/world-malaria-report-2016/en/

[3] Khadija hamad, Mustafa Albudolh- (2012)-" volunteer training guide in the work of the malaria control ". MOH.Sudan

[4] Malaria fact sheets 2016. Accessed 12 January 2017 http://www.who.int/mediacentre/factsheets/fs094/en/

[5] Pesticides and health hazards. Germany 2016. Accessed January 11, 2017, http://www.pangermany.org/download/Vergift_EN-201112-web.pdf.

[6] Canadian center for occupational health and safety Pesticides.2017. Accessed Feb 19, 2017, http://www.ccohs.ca/oshanswers/chemicals/pesticides/

[7] National Pesticide Information Center, Accessed Mar, 92017 http://npic.orst.edu/factsheets/Diazgen.htm.

*Corresponding author.

E-mail address: mohsm71@ yahoo.com 